\title{
Tuberculose associada a nefrocalcinose em um lactente
}

\author{
Tuberculosis associated with nephrocalcinosis in an infant
}

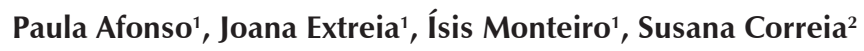 \\ ${ }^{1}$ Internas do Internato Complementar de Pediatria, Serviço de Pediatria, Centro Hospitalar Barreiro Montijo - EPE, Portugal; ${ }^{2}$ Assistente Hospitalar de Pediatria, Serviço \\ de Pediatria, Centro Hospitalar Barreiro Montijo - EPE, Portugal.
}

\section{RESUMO}

Objetivos: Relatar um caso clínico de tuberculose de apresentação não usual.

Descrição do caso: Uma lactente de oito meses, sem infecção pelo vírus de imunodeficiência humana (HIV), filha de mãe seropositiva para HIV e com tuberculose pulmonar, foi internada por febre com 15 dias de evolução, sem outra sintomatologia. A radiografia de tórax revelou múltiplos focos de hipotransparência bilateralmente e a prova de tuberculina $8 \mathrm{~mm}$. A doente não havia recebido a vacina BCG. Realizou broncofibroscopia que evidenciou compressão extrínseca da árvore traqueobrônquica, causada por múltiplas adenopatias, confirmadas por ressonância magnética nuclear do mediastino. Na ecografia abdominal foram encontrados aspectos sugestivos de nefrocalcinose. Os estudos do metabolismo cálcio-fósforo e da função renal não revelaram alterações. Iniciou terapêutica antibacilar tripla e corticoterapia. Foi isolado Mycobacterium tuberculosis no lavado bronco-alveolar. Verificou-se boa evolução clínica, tendo alta com 27 dias de terapêutica antibacilar. Conclusões: Este caso clínico destaca-se pela forma incomum de apresentação da tuberculose, com a presença de nefrocalcinose. As perturbações do metabolismo do cálcio associadas à tuberculose são raras, mas têm implicação no seguimento e no prognóstico.

DESCRITORES: TUBERCULOSE; NEFROCALCINOSE; TRANSTORNOS DO METABOLISMO DO CÁLCIO; HIV-1.

\section{ABSTRACT}

Aims: To report a case of tuberculosis with unusual presentation.

Case description: An eight months old infant without infection by the human immunodeficiency virus (HIV), born of an HIV-positive mother with pulmonary tuberculosis, was hospitalized for fever lasting 15 days, with no other symptoms. Chest radiography revealed multiple bilateral nodular opacities and the tuberculin test was $8 \mathrm{~mm}$. The patient had not received BCG vaccination. Bronchoscopy showed extrinsic compression of the tracheobronchial tree, caused by multiple adenopathies, confirmed by nuclear magnetic resonance imaging of the mediastinum. Abdominal ultrasound was suggestive of nephrocalcinosis. Phospho-calcium metabolism and renal function studies showed no alterations. Triple antituberculous therapy and corticosteroid were started. Mycobacterium tuberculosis was isolated in bronchoalveolar lavage. There was good clinical outcome and the patient was discharged with 27 days of antituberculosis therapy.

Conclusions : This case stands out for its unusual presentation, with the presence of nephrocalcinosis. Disturbances of calcium metabolism associated with tuberculosis are rare, but have implications for the follow-up and prognosis.

KEY WORDS: TUBERCULOSIS; NEPHROCALCINOSIS; CALCIUM METABOLISM DISORDERS; HIV-1. 


\section{INTRODUÇÃO}

A tuberculose (TB) em idade pediátrica continua a ser um problema de saúde pública mundial, correspondendo a 6-7\% de todos os casos da doença. ${ }^{1,2}$ Alguns estudos demonstram que o número de casos na infância mantém-se elevado nas últimas décadas. ${ }^{3} \mathrm{Em}$ Portugal a sua incidência tem diminuido, mantendose contudo ainda elevada. Em 2012 foram notificados 2.480 novos casos, sendo 69 em doentes com menos de 15 anos. ${ }^{1}$ Os esforços para melhorar o diagnóstico, a terapêutica e o controle epidemiológico dessa infecção são centrados no adulto, sendo a TB na criança relativamente negligenciada. ${ }^{2}$ A infecção pelo Mycobacterium tuberculosis atinge maioritariamente o pulmão e na infância é frequentemente primária. ${ }^{4,5} \mathrm{As}$ crianças, após exposição a um adulto infectado, ficam suscetíveis à progressão da TB latente para doença clínica. ${ }^{4}$ A semiologia da infecção pelo M. tuberculosis é variada e inespecífica, assim como as alterações a ela associadas nos exames de imagem. ${ }^{6} \mathrm{Na}$ primoinfecção, a febre é o sintoma mais frequente $(70 \%)$, podendo-se associar a dor torácica tipo pleurítica e derrame pleural, sendo o cansaço e a faringite raros. Geralmente não há alterações ao exame objetivo. ${ }^{4}$

As perturbações do metabolismo do cálcio são frequentes na criança, porém a sua associação a doenças granulomatosas, nomeadamente a TB, é rara. ${ }^{7}$ Existem poucos casos descritos na literatura da associação de hipercalcemia e TB, o que justifica a publicação deste caso. ${ }^{8-10}$

Este relato de caso segue os preceitos éticos para publicações sobre seres humanos e foi aprovado pela Comissão de Ética do Hospital Nossa Senhora do
Rosário, Centro Hospitalar Barreiro Montijo, EPE, Barreiro, Portugal.

\section{RELATO DO CASO}

Apresenta-se o caso clínico de uma lactente de oito meses, caucasiana, negativa para vírus de imunodeficiência humana (HIV), mas cuja mãe era seropositiva para HIV e havia sido hospitalizada com TB pulmonar. Dos antecedentes pessoais salienta-se a não realização de vacina $\mathrm{BCG}$ e o seguimento em ambulatório de infecções congénitas, tendo cinco amostras de sangue com PCR (polimerase chain reaction) negativa para HIV-1 (ao nascimento, com seis semanas, com oito semanas, com quatro meses e com seis meses de vida). Foi internada por picos febris (temperatura axilar $>38^{\circ} \mathrm{C}$ ) que se repetiam há 15 dias, intercalados com períodos de apirexia de 12 horas, sem outros sintomas ou sinais. O exame objetivo na admissão era normal. Nos exames complementares apresentava anemia, leucocitose e proteína $\mathrm{C}$ reativa (PCR) 20,3 mg/L (valor de referência inferior a $5 \mathrm{mg} / \mathrm{L}$ ) (Tabela 1). A radiografia de tórax revelou múltiplos focos de hipotransparência difusos bilateralmente (Figura 1) e a prova da tuberculina foi positiva, com induração de $8 \mathrm{~mm}$ (sem BCG prévia). Pela história clínica, exames complementares de diagnóstico e contexto epidemiológico materno, admitiu-se a hipótese diagnóstica de TB pulmonar/miliar, pelo que iniciou no terceiro dia de hospitalização, terapêutica antibacilar tríplice (isoniazida $10 \mathrm{mg} / \mathrm{kd} / \mathrm{dia}$, rifampicina $15 \mathrm{mg} / \mathrm{kg} / \mathrm{dia}$ e pirazinamida $30 \mathrm{mg} / \mathrm{kg} / \mathrm{dia}$ ), acrescida de prednisolona $1 \mathrm{mg} / \mathrm{kg} / \mathrm{dia}$. A corticoterapia foi suspensa após sete dias, ao ser descartada a hipótese de TB miliar.
Tabela 1. Valores laboratoriais, realizados ao longo da hospitalização de uma lactente de oito meses de idade com tuberculose e nefrocalcinose, com início da terapêutica antibacilar tripla e corticoterapia no terceiro dia.

\begin{tabular}{|lcccc}
\multicolumn{1}{c}{ Exames laboratoriais } & Dia $\mathbf{1}$ & Dia $\mathbf{5}$ & Dia $\mathbf{1 6}$ & Dia $\mathbf{3 2}$ \\
\hline Hemoglobina (g/dL) & 10,3 & 8,8 & 10,8 & 11,7 \\
\hline Leucócitos (/L) & 14300 & 35810 & 23400 & 8360 \\
\hline Neutrófilos (\%) & $41,5 \%$ & $79,2 \%$ & $69,5 \%$ & $12,5 \%$ \\
\hline Linfócitos (\%) & $50,9 \%$ & $15,9 \%$ & $24,6 \%$ & $73,7 \%$ \\
\hline Plaquetas (/L) & 529000 & 555000 & 713000 & 443000 \\
\hline Proteína C reativa (mg/L) & 20,3 & 23,7 & & \\
\hline Velocidade de sedimentação (mm/h) & & 84 & & 40 \\
\hline Ureia (mg/dL) & & 9 & 21 & 10 \\
\hline Creatinina (mg/dL) & 0,34 & 0,23 & 0,45 & 0,38 \\
\hline Aspartato aminotransferase (UI/L) & & 24 & 32 & 37 \\
\hline Alanina aminotransferase (UI/L) & & 10 & 13 & 13 \\
\hline Ácido úrico (mg/dL) & & & 6,3 & 4,3 \\
\hline Cálcio (mg/dL) & & & 10,8 & 11,2 \\
\hline Fósforo (mg/dL) & & 6 & 5,8 \\
\hline
\end{tabular}




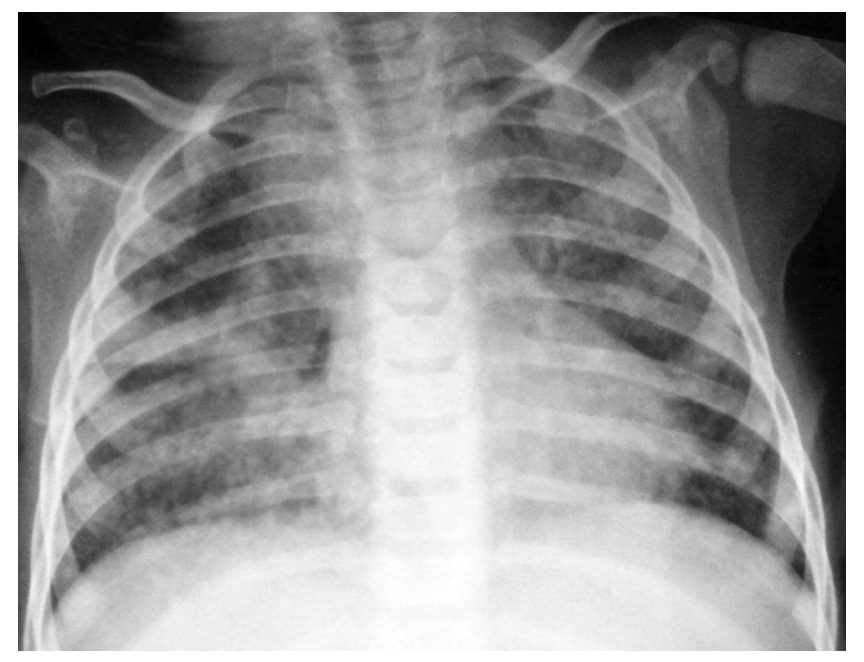

Figura 1. Radiografia de tórax: múltiplos focos de hipotransparência difusos bilateralmente.

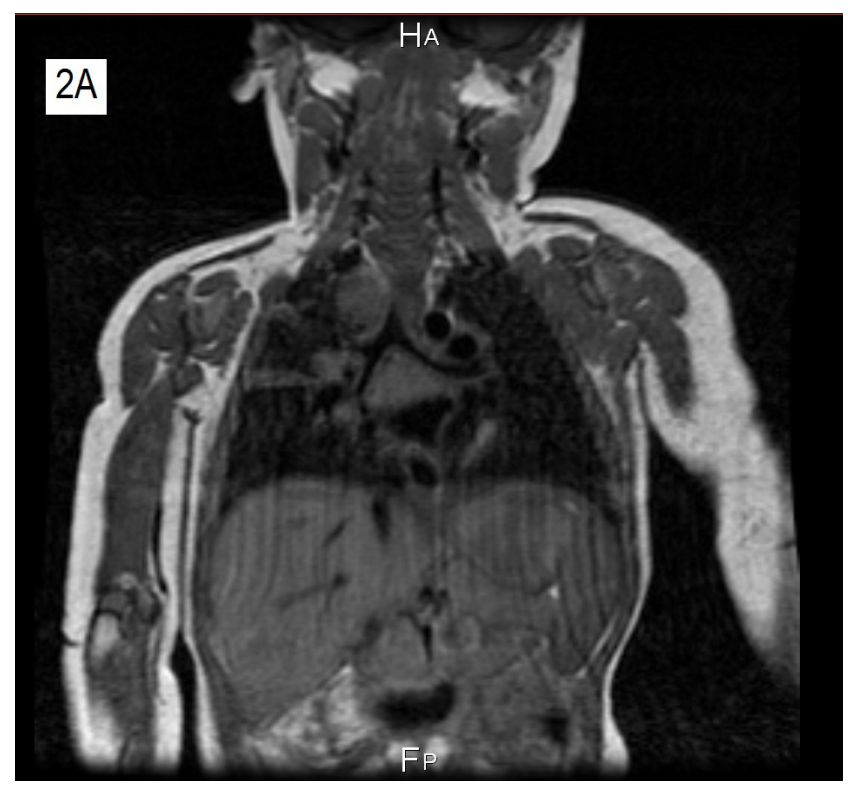

Efetuou broncofibroscopia com lavado broncoalveolar que mostrou compressão extrínseca dos $2 / 3$ inferiores da traqueia e do ramo anterior do brônquio lobar superior direito. Para melhor caracterização das alterações descritas foi feita ressonância magnética nuclear do mediastino, que confirmou múltiplas adenopatias responsáveis pela compressão traqueobrônquica (Figura 2A e 2B).

Para esclarecimento de possível envolvimento extrapulmonar, a doente foi examinada por um oftalmologista, não se tendo observado tubérculos coroideus. A ecografia abdominal revelou inversão da normal diferenciação e ecogenicidade cortico-medular, aspectos sugestivos de fase inicial de nefrocalcinose (Figura 3). O estudo analítico do metabolismo cálciofósforo e da função renal (Tabela 1), efetuado ao nono dia de terapêutica antibacilar, não revelou alterações. Durante a hospitalização realizou hemoculturas, que foram negativas, tendo-se isolado posteriormente M. tuberculosis sensível à terapêutica antibacilar instituída, em cultura do suco gástrico e no lavado bronco-alveolar.

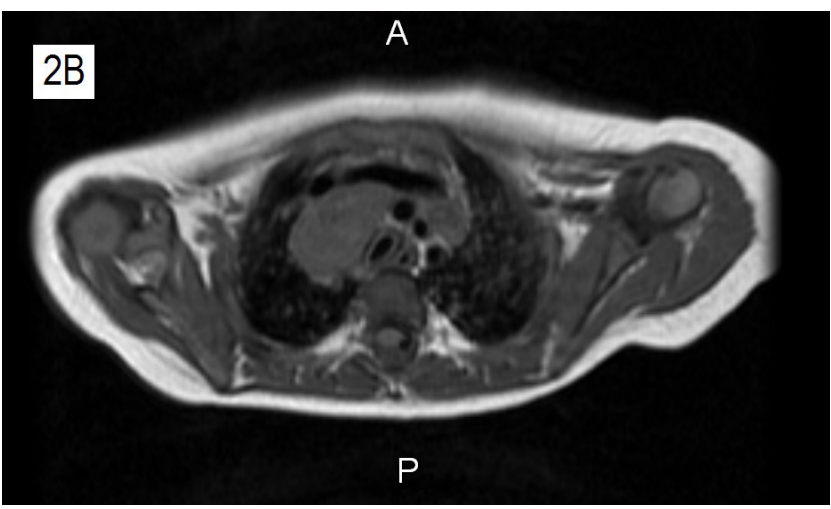

Figuras 2A e 2B. Ressonância nuclear magnética do mediastino: extenso envolvimento adenopático mediastínico causando compressão traqueobrônquica.

Veja esta imagem em maior definição:

Fig. 2A: http://revistaseletronicas.pucrs.br/ojs/index.php/scientiamedica/article/view/16328/11510

Fig. 2B: http://revistaseletronicas.pucrs.br/ojs/index.php/scientiamedica/article/view/16328/11511

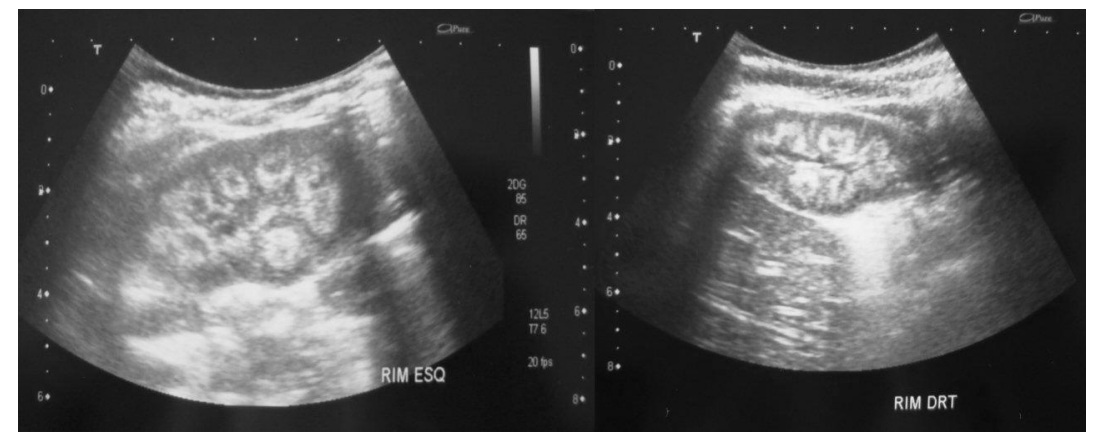

Figura 3. Ecografia abdominal: inversão da normal diferenciação e ecogenicidade cortico-medular, aspectos sugestivos de fase inicial de nefrocalcinose.

Veja esta imagem em maior definição:

http://revistaseletronicas.pucrs.br/ojs/index.php/ scientiamedica/article/view/16328/11512 
Verificou-se boa evolução clínica e laboratorial (Tabela 1), ficando apirética no segundo dia de terapêutica, com bom estado geral e razoável progressão ponderal (peso na alta $7.100 \mathrm{~g}$, tendo aumentado $650 \mathrm{~g}$ em 27 dias). Repetiu radiografia de tórax após 24 dias de terapêutica, que se revelou sobreponível à da admissão. Teve alta após 27 dias, referenciada ao Centro de Diagnóstico Pneumológico e à Consulta de Pediatria.

\section{DISCUSSÃO}

Neste caso clínico salienta-se a associação de TB com nefrocalcinose, esta detectada pela ecografia abdominal. Existem poucos casos descritos na literatura da associação de hipercalcemia e TB. ${ }^{12,13} \mathrm{~A}$ hipercalcemia que ocorre na TB e em outras doenças granulomatosas ${ }^{8}$ deve-se ao metabolismo alterado da vitamina $\mathrm{D}$, com aumento da produção de calcitriol por macrófagos ativados retidos nos alvéolos pulmonares e nas áreas de inflamação. ${ }^{6,13} \mathrm{~A}$ descrição dessa associação varia na literatura de 2,3 a $28 \%$, conforme a área geográfica, sendo esta diferença na frequência possivelmente relacionada à diferente ingestão de cálcio e vitamina $\mathrm{D}$ pelos hábitos alimentares..$^{10}$

As perturbações do metabolismo do cálcio associadas à $\mathrm{TB}$, apesar de raras, têm implicação no tratamento, prognóstico e seguimento dos doentes, motivo pelo qual os autores consideram pertinente a apresentação deste caso clínico.
A terapêutica da nefrocalcinose associada à TB fundamenta-se no início precoce da terapêutica antibacilar e do controle da hipercalcemia. A corticoterapia foi iniciada nesta doente por suspeita de TB miliar e não para o tratamento da hipercalcemia, cuja suspeita ainda não havia sido levantada. Contudo, essa terapêutica pode ter tido influência na concentração sérica de cálcio (que tende a diminuir com o tratamento específico acrescido da corticoterapia, sendo a resposta geralmente completa entre o sétimo e décimo dia de terapêutica). ${ }^{10} \mathrm{~A}$ ausência de alterações laboratoriais do metabolismo cálcio-fósforo pode, portanto, dever-se ao fato dessa avaliação ter sido feita no nono dia de terapêutica. Apesar da influência na calcemia, a corticoterapia aparentemente não interfere na evolução para nefrocalcinose associada à $\mathrm{TB}$, motivo pelo qual atualmente não está recomendada. ${ }^{10}$

A hipercalcemia e a hipercalciúria associadas à TB são frequentemente assintomáticas na fase inicial. A demora no diagnóstico e no tratamento da infecção podem resultar em nefrocalcinose, litíase e insuficiência renal. ${ }^{6}$ Nestas situações, após resolução da TB, os doentes têm de manter seguimento clínico, imagiológico e avaliação regular da função renal, de modo ao reconhecimento oportuno da presença de litíase ou de deterioração da função renal.

Concluindo, este caso clínico destaca-se pela forma incomum de apresentação da TB, com a presença de nefrocalcinose. As perturbações do metabolismo do cálcio associadas à TB são raras, mas têm implicação no seguimento e no prognóstico do paciente.

\section{REFERÊNCIAS}

1. Wold Health Organization. Global tuberculosis report 2013 [Internet]. WHO; 2013 [cited 2014 Jan 2]. Available from: http://www.who. int/tb/publications/global_report/en/

2. Chen S, Liang K. Updated diagnosis and treatment of childhood tuberculosis. World J Pediatr. 2013;9(1):9-16.

3. Leite A, Carvalho I, Tavares E, Vilarinho A. Tuberculose doença - Casuística de um serviço de pediatria no século XXI. Rev Port Pneumol 2009;15(5):771-82.

4. Hay Jr WW, Levin MJ, Sondheimer JM, Deterding RR (eds.). Current Diagnosis \& Treatment: Pediatrics, 19th ed. New York: Mc Graw Hill; 2009.

5. Schluger NW, Rom WN. Current approaches to the diagnosis of active pulmonary tuberculosis. Am J Respir Crit Care Med. 1994;149(1): 264-7.

6. Junior C, Monteiro F, Cardoso G. Manifestações endócrino-metabólicas na tuberculose. Rev Port Pneumol. 2003;9(4):353-8.

7. Diaz R. Calcium disorders in children and adolescents. In: Lifshitz F. (Ed.) Pediatric Endocrinology, Vol 2. New York: Informa Healthcare USA Inc; 2007. p. 475-95.

8. Yilmaz R, Kundak A. Idiopathic infantile hipercalcemia or na extrapulmoary complication of tuberculosis. Tuberk Toraks. 2013;61(1): 43-6.

9. Tresoldi A. Hypercalcemia and multiple osteolytic lesions in child with disseminated paracoccidioidomycosis and pulmonary tuberculosis. J Pediatr (Rio J). 2005;81(4):349-52. 
10. Chan TY. Differences in vitamin D status and calcium intake: possible explanations for the regional variations in the prevalence of hypercalcemia in tuberculosis. Calcif Tissue Int. 1997;60(1):91-3.

11. Gerritsen J. Knol K. Hypercalcaemia in a child with miliary tuberculosis. Eur J Pediatr. 1989;148(7):650-1.

12. Okascharoen C, Nuntnarumit P, Sirinavin S. Neonatal tuberculosis associated with shock, disseminated intravascular coagulation, hemophagocytic syndrome, and hypercalcemia: a case report. J Perinatol 2003;23(1):79-81.

13. Sharma OP. Hypercalcemia in granulomatous disorders: a clinical review. Curr Opin Pulm Med 2000;6(5):442-7. 